\title{
The prevalence of fibrocystic changes of breast tissue of patients who underwent reduction mammoplasty in Rasool-Akram, Firuzgar and Sadr Hospitals during 2007-2012
}

\author{
Mostafa Hosseini", Adnan Tizmaghz, Hamidreza Alizadeh Otaghvar, Marjan Shams
}

Surgical department of Iran University of medical science, Tehran, Iran

Email address:

mhosseini260@yahoo.com (M. Hosseini)

To cite this article:

Mostafa hosseini, Adnan Tizmaghz, Hamidreza Alizadeh Otaghvar, Marjan shams. The Prevalence of Fibrocystic Changes of Breast Tissue of Patients who Underwent Reduction Mammoplasty in Rasool-Akram, Firuzgar and Sadr Hospitals during 2007-2012. Advances in Surgical Sciences. Vol. 2, No. 1, 2014, pp. 5-8. doi: 10.11648/j.ass.20140201.12

\begin{abstract}
Introduction: Fibrocystic changes are considered as common and benign changes in the breast tissue. This study aimed to determine the prevalence of pathologic changes Including fibrocystic changes, hyperplasia, and carcinoma in breast tissue specimens of patients underwent reduction Mammoplasty.Methods: 128 consecutive patients over a period of 5 years from 2007 to 2012, who were admitted at the Rasool-Akram, Firoozgar, and Sadr Hospitals for reduction mammoplasty, were investigated in this study. In all patients an average of 500 grams of breast tissue from each side during mammoplasty was sent for pathologic evaluation. The variables measured in the study included age, fibrocystic changes, and hyperplastic changes in the pathology specimens of these patients. Data analysis was performed using SPSS 18 software. Results: 71 patients $(55.5 \%)$ had fibrocystic changes. 6 patients $(4.7 \%)$ were reported to have hyperplasia. Carcinoma was not observed in any of the samples. The prevalence of fibrocystic changes increased with age. Hyperplastic changes were not associated with age and with fibrocystic changes. But it was the most common in the ages between 31 and 40 years. Conclusion: Fibrocystic breast changes are common, and their prevalence increases with age. However, they are not associated with hyperplasia and cancer risk.
\end{abstract}

Keywords: Breast Fibrocystic Changes, Pathology, Mammoplasty

\section{Introduction}

Most of the women suffer from fibrocystic changes of the breast during their life time [ 1].This benign breast change is very common and develops in more than $50 \%$ of women. Most of these women are aged between 40 to 49 years [2]. This disease has been recognized as fibrocystic breast disease, fibrocystic mastopathy, mammary dysplasia and chronic cystic mastitis. Although specific reason shave not been reported for these changes but it is believed that the pathogenesis of the fibrocystic changes of the breast is because of the response of the breast tissue to the hormones of the body. The symptoms found in this disease include pain, tenderness, nipple discharge, fullness or heaviness and multiple round and soft palpable mass. These symptoms are severe in the premenstrual phase. These symptoms can disrupt the quality of life of the affected people. It has been reported that the fibrocystic changes are a risk factor for breast cancer [4] and based on these studies, these people are at a risk of breast cancer 3 to 4 times more than other people [5]. Researches performed in this field showed that a kind of fibrocystic changes known as epithelial proliferation (hyper plastic) has a significant impact on the advancement of breast cancer in human beings. Considering the fact that these events have a negative impact on the quality of life of affected people. We surveyed the prevalence of fibrocystic changes in the pathologic specimen of patients who underwent reduction mammoplasty surgery to determine the presence of hyperplastic changes in this group of people as an example of the healthy women of the community 


\section{Methods}

In this study, population under survey included women referred to RasoolAkram and Firuzgar and Sadr hospital for reduction mammoplasty. By sampling method, all the patients who underwent bilateral mammoplasty from 2007 to 2012 were included in the study and were evaluated. After obtaining informed consent from patients to use their samples in our study, In all patients an average of 500 gram of tissue was taken from each breast during mammoplasty and was sent for pathologic evaluation. The variables of the study included age, presence of fibrocystic changes and presence of hyperplastic changes in the pathologic specimens of these patients. Required information was extracted from the medical records and was recorded in the check list. Finally the collected data was analyzed by using SPSS 18 software. Mean central index for description of quantitative data and frequency percentage for description of qualitative data and the distribution index of standard deviation was used. To determine the relationship between age and the presence of fibrocystic changes and considering the normal distribution of data (after checking with one sample KS) chi 2 test was used to survey the relation between age groups.

\section{Results}

In the present study, 128 consecutive patients were included who underwent reduction mammoplasty. Average age of these patients was $41 / 4$ (in the range of 20 to 69 years). 23 of these patients(18\%) were in the age group of 20 to 30 years, 46 patients $(9 / 35 \%)$ were in the age group of 31 to 40 years, 33 patients $(8 / 25)$ in the age group of 41 to 50 years, 23 patients $(18 \%)$ in the age group of 51 to 60 years and 3 patients $(3 / 2 \%)$ in the age group between 61 to 70 years. The pathologic samples taken from the breast tissue of the patients under study revealed that 71 patients (55/5\%) suffered from fibrocystic changes. In addition to it, pathologic specimen of 6 patients $(7 / 4 \%)$ reported hyperplasia. Mixed Hyperplasia and fibrocystic changes were not found in any of the samples. Carcinoma was not detected in any of the samples. The mean age of patients with fibrocystic changes in breast tissue was significantly higher than other patients $(43 / 1+$ + $9 / 4$ years in comparison with $(39 / 2+10 / 6$ years, $p=0.03)$. Moreover the prevalence of fibrocystic changes was higher in older age groups. These changes in the age group of 20 to 30 years were (26/1\%), and between 31 to 40 years it was $(54 / 3 \%)$, in the age group between 41 to 50 years it was $66 / 7 \%$ and atmore than 50 years of age it was $69 / 2 \%(p=0.008)$ (figure 1$)$. The mean age of patients with hyper plastic changes had no significant and meaningful differences from other patients' $(38 / 8+6 / 7$ years $)$ in comparison with $41 / 5+$ + $10 / 2$ years respectively $(\mathrm{p}=0.52)$. But the presence of hyper plastic changes in the breast tissue of patients with the age group of 31 to 40 years was more common than other age groups $(8 / 7 \%)$ figure 2.

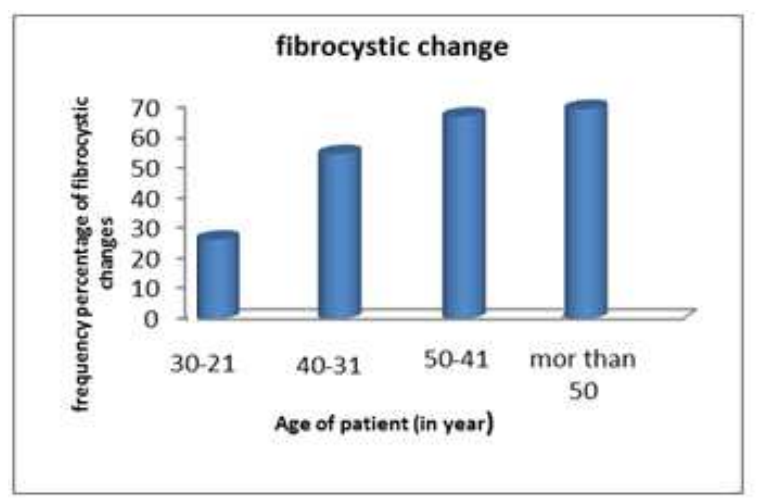

Figure 1. Distribution of the fibrocystic changes reported through the pathology of the breast tissue samples of the patients under study on the basis of different age groups.

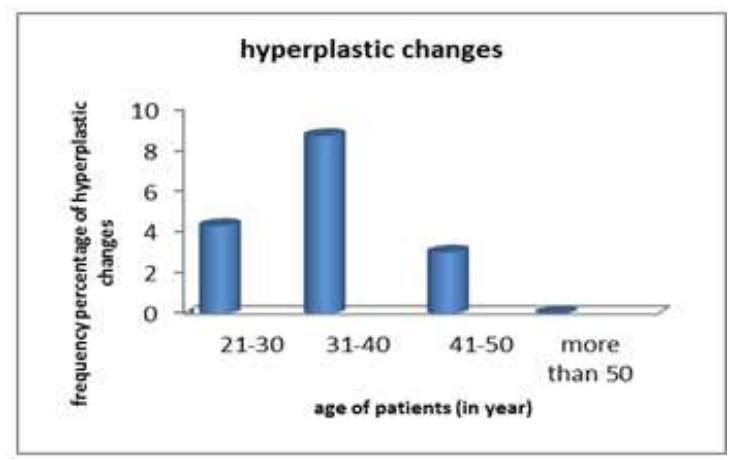

Figure 2. Distribution of the hyper plastic changes reported through the pathology of the breast tissue samples of the patients under study on the basis of different age groups.

\section{Discussion}

Normal breast tissue is composed of glandular, connective and fatty tissue. The tissue is clustered into lobes and each lobe has a duct that leads to the nipple. Breast tissue is sensitive to the normal ovarian hormonal changes associated with the menstrual cycle. Breast changes, including fullness and tenderness, normally occur prior to the onset of the menstrual period and are caused by the hormonal fluctuations that occur late in the menstrual cycle. These symptoms usually subside spontaneously within 5-7 days of the onset of bleeding. Benign breast conditions refer to physical changes in the breast that are non-cancerous. The symptoms of benign conditions are similar to those found in breast cancer and may cause great concern until evaluated and explained by a qualified health professional. Two of the most common benign breast conditions are Fibrocystic Breast Condition (FBC) and Fibroadenoma [15]. Fibrocystic Breast Condition (also called "mammary dysplasia," "benign breast disease," and "diffuse cystic mastopathy") is the most common of the benign breast conditions. With an estimated incidence of over $60 \%$ of women, many consider it a variation of normal. Fibrocystic breast changes occur between 20 and 50 years of age and subside with menopause. They are characterized by generalized tenderness and an uneven, bumpy texture caused by increased engorgement of the glands forming 
multiple small fluid-filled cysts clustered within the breast. Occasionally there is some spontaneous nipple discharge noted. Fibrocystic breast changes usually involve the entire breast but may be more severe in the upper, outer area of the breast. The symptoms may be present throughout the month but normally increase as the menstrual period approaches. It is estimated that $50 \%$ of American women may experience some fibrocystic breast changes at some time in their lives. FBC may affect one or both breasts and may change in severity from month to month.

The patient history and exam usually diagnose FBC. It is not normally necessary to have diagnostic tests such as ultrasound or mammography done unless there are abnormal physical findings. It is important to do a monthly breast self-exam (BSE). Breast self-exam may be more challenging for a woman experiencing fibrocystic changes; therefore, it is especially important that she be keenly aware of the normal texture of her breast tissue. Any significant changes should be reported to a health care provider [16-20].

The fibrocystic changes of the breast are considered one of the common and benign pathology and from the pathologic view three main structures are observed as cyst, fibrosis and adenosis. The prevalence of these changes has been reported to be different indifferent articles. Most of the studies performed in this field, reveal the prevalence of fibrocystic changes by using the samples from the breast tissue of healthy individuals who underwent reduction mammoplasty, so that its prevalence in healthy individuals of the community is determined [9-6]. Also in the present study 128 consecutive patients with a mean age of $41 / 4$ years who underwent reduction mammoplasty were enrolled. After surveying the pathologic samples taken from the breast tissue of these patients it was found that $55 / 5 \%$ of samples had fibrocystic changes and $4 / 7 \%$ of samples reported hyperplasia. There was no evidence of carcinoma in any of these samples. In a similar study conducted in Turkey by Ayhan et al and colleagues, 47/0\% of fibrocystic changes were reported in the women who underwent reduction mammoplasty from the samples taken from the breast tissue. Adenosis was found in $4 / 4 \%$ of samples and in $3 / 1 \%$ of samples fibroadenoma was seen. Epithelial hyperplasia was reported in $1 / 3 \%$ of samples, metaplasia of apocrine in $0 / 6 \%$ and carcinoma of intraductalin $0 / 6 \%$ of samples [10]. In a recent study Kyriopoulos and colleagues found benign pathologic changes including atypical mild ductal hyperplasia, fibrocystic changes, adenosis, fibro adenoma, and lobularatrophy was found in $67 / 4 \%$ of the patients who underwent bilateral reduction mammoplasty. The prevalence of occult carcinoma was also observed in $1 / 55 \%$ of patients [11]. In another retrospective study by Clark and colleagues incidence of benign and pre-cancerous lesions in breast reduction samples over a period of 5 years was investigated. Among 562 patients, 52/7\% suffered from non-proliferative and proliferative lesions [9].Pitanguy and colleagues reported benign pathologic changes of the breast including fibrocystic changes and fibro adiposity in $80 / 8 \%$ of patients. The prevalence of benign tumors including fibro adenoma was $2 / 2 \%$ in their study. Abundance of malignant tumors among all the patients was $0.5 \%$. Most of the histopathological changes were observed in patients between 30 to 50 years [12]. In Samdanci and his colleagues study also, in $2 / 9 \%$ of these patients undergoing mammoplasty, lobular or atypical ductal hyperplasia was observed. $0 / 3 \%$ of these patients suffered from insitu lobular carcinoma. But invasive carcinoma was not found in these patients [7]. In Dotto and hiscolleagues study also $18 \%$ of patients undergoing reduction mammoplasty had low risk ductal intra epithelial neoplasia or intra ductal hyperplasia. $5 \%$ of patients suffered from intra epithelial ductal neoplasia, 3\% had intra epithelial lobular neoplasia and in $0 / 2 \%$ of patients tubular carcinoma was observed [6]. In Blansfield study, $89 \%$ of patients had normal breast tissue. $10 \%$ of patients had proliferative changes and among them $5 \%$ were without atypia, $3 \%$ with atypia, $2 \%$ with sclerosing adenosis and $0 / 5 \%$ had papilomatose and lobular carcinoma in situ [13]. In Viana and his colleagues study also in 2005 dysplasia and fibro adiposity was reported in $69 / 1 \%$ of samples from patients undergoing reduction mammoplasty. Atypical ductal hyperplasiawas found in $0 / 6 \%$ of samples and carcinoma was found in 1/1\% [14]. In Ambave and his colleagues study also significant pathologic findings(carcinoma and atypical hyperplasia) were found in $12 / 4 \%$ of samples obtained from reduction mammoplasty. Rate of carcinoma was $4 \%$ in all cases, $6 / 2 \%$ in patients older than 40 years and $7 / 9 \%$ in patients older than 50 years [8]. Thus on the basis of the results of our study and other studies in this field, prevalence of fibrocystic changes is very high but hyperplasia and carcinoma of the breast tissue samples from patients undergoing mammoplasty is very low. We did not observe any case of carcinoma in our study. However other studies have reported an approximate prevalence of $2-1 \%$ among these cases and this difference can be due to the lower sample size of our study. Overall, age is significantly associated with the pathologic abnormalities in the breast tissue [8]. Based on the findings of our study, prevalence of fibrocystic changes increased with age. The prevalence of hyper plastic changes was not associated with age. Similarly, in Blansfield study $95 \%$ of patients having proliferative changes were in the age group of more than 30 years. Women between age group of 30 to 39 years are at a higher risk for proliferative changes of the breast [13]. However contrary to our results, in Dotto's study also the abundance of hyperplastic lesions increased with increasing age [6]. This difference could be due to the differences in population under study, methods of breast tissue biopsy and number of specimens taken from it. As has been mentioned above increased number of biopsies from breast tissue is associated with incidence of abnormal pathologic findings in patients older than 40 years. This indicates that biopsy of breast tissue inpatients more than 
40 years undergoing reduction mammoplasty should be performed with more care [8].

\section{Conclusion}

Breast reduction surgery has been nominated as an auxiliary method for detecting malignancy. However, this method is not liberally available for all suspects. In the patients who undergo breast reduction surgery, the techniques provides with ample amount of the tissue for thorough histopathologic examination and exact screening for possible atypical entities .[21]. Overall in our study prevalence of benign fibrocystic changes of the breast tissue samples obtained from reduction mammoplasty was $55 / 5 \%$ and prevalence of hyperplasia was $4 / 7 \%$ and incidence of fibrocystic changes was significantly associated with the age of patients.

\section{References}

[1] Wu C, Ray RM, Lin MG, et al. A case-control study of risk factors forfibrocystic Breast conditions. Am J Epidemiol 2004; 160:945-960.

[2] Kabat GC, Jones JG, Olson N. A multi-center prospective cohort study ofbenign breast disease and risk of subsequent breast cancer. Cancer Causes Control2010; 21:821-828.

[3] Boschert MT, Barone CM, Puckett CL. Outcome analysis of reductionmammaplasty. PlastReconstr Surg. 1996;98:451-4.

[4] London SJ, Connolly JL, Schnitt SJ, Colditz GA. A prospectivestudy of benignbreast disease and the risk of breast cancer.JAMA 1992; 267:941-944.

[5] Cotran., Kumar., Collins Robbins Pathologic basis of disease, 6 thed b Philadelphia, Saunders company, 1999, PP: 1098-1100.

[6] Dotto J, Kluk M, Geramizadeh B, Tavassoli FA. Frequency of clinically occultintraepithelial and invasive neoplasia in reduction mammoplasty specimens: astudy of 516 cases. Int J SurgPathol. 2008 Jan;16(1):25-30.

[7] Samdanci ET, Firat C, Cakir E, Ak M, Sayin S, Nurkabul Z. The incidence ofnon-proliferative and precancerous lesions of reduction mammoplasty: evaluationof 273 cases. Eur Rev Med PharmacolSci 2011;15(10):1207-11.
[8] Ambaye AB, MacLennan SE, Goodwin AJ, Suppan T, Naud $\mathrm{S}$, Weaver DL.Carcinoma and atypical hyperplasia in reduction mammaplasty: increasedsampling leads to increased detection. A prospective study.PlastReconstrSurg2009 Nov;124(5):1386-92.

[9] Clark CJ, Whang S, Paige KT. Incidence of precancerous lesions in breastreduction tissue: a pathologic review of 562 consecutive patients. PlastReconstrSurg 2009;124(4):1033-9.

[10] Ayhan S, Başterzi Y, Yavuzer R, Latifoğlu O, Cenetoğlu S, Atabay $\mathrm{K}$, et al.Histologic profiles of breast reduction specimens. Aesthetic PlastSurg 2002;26(3):203-5.

[11] Kyriopoulos E, Kakagia D, Zapandioti P, Papaliodi E, Tsoutsos D. Pathologicfindings in breast reduction specimens: detection of occult premalignant andcancerous lesions. Onkologie. 2012;35(10):583-6.

[12] Pitanguy I, Torres E, Salgado F, PiresViana GA. Breast pathology and reduction mammaplasty. PlastReconstr Surg. 2005 Mar;115(3):729-34; discussion735.

[13] Blansfield JA, Kukora JS, Goldhahn RT Jr, Buinewicz BR. Suspicious findingsin reduction mammaplasty specimens: review of 182 consecutive patients. AnnPlast Surg. 2004 Feb;52(2):126-30.

[14] Viana GA, Pitanguy I, Torres E. Histopathological findings in surgicalspecimens obtained from reduction mammaplasties. Breast. 2005 Jun;14(3):242-8

[15] http://www.mckinley.illinois.edu/handouts/breast_health/bre ast health.html

[16] Berek and Novaks, Gynecology, 14th edition, 2007, pages 637-659.

[17] Up To Date, 2012

[18] Stenchever, Morton A., Droegemuller, William, Herbst, Arthur, Mishell, Daniel R., Comprehensive Gynecology, 54th Edition; Mosby 2007, pages 327-357.

[19] Benign Breast Disease and Breast Cancer Tutorial; Dr. William H. Goldberg, University of Wisconsin

[20] National Institute of Health. "Breast Diseases" MEDLINEplus Medical Encyclopedia, a service of the U.S. National Library and the National Institute of Health web site: http://www.nlm.nih.gov/medlineplus/

[21] Brown, M.H., M. Weinberg, N. Chong, R. Levine and E. Holowaty, 1999. A cohort study of breast cancer risk in breast reduction patients. Plast. Reconstr. Surg., 103: 16741681. 